\title{
In-situ TEM Study of Lithiation of Si and Phase Transformation
}

\author{
Chong-Min Wang, Meng Gu, Zhiguo Wang, Fei Gao, Ji-Guang Zhang, Donald R. Baer, \\ S. Suntharampillai Thevuthasan, Nigel Browning, and Jun Liu \\ Pacific Northwest National Laboratory, Richland, WA 99352, USA
}

Silicon as a candidate anode material for rechargeable lithium ion battery shows several unique characteristics. It has a theoretical gravimetric capacity of $\sim 4200 \mathrm{mAh} \mathrm{g}^{-1}$ and a volumetric capacity of $\sim 8500 \mathrm{mAh} \mathrm{cm}^{-3}$. Upon lithiation, both crystalline and amorphous silicon will transform to amorphous $\mathrm{Li}_{\mathrm{x}} \mathrm{Si}\left(\mathrm{a}-\mathrm{Li} \mathrm{i}_{\mathrm{x}} \mathrm{Si}\right)$, a process termed as electrochemical driven solid state amorphization [1]. With continued enrichment of Li in the a- $\mathrm{Li}_{\mathrm{x}} \mathrm{Si}$, the a- $\mathrm{Li}_{\mathrm{x}} \mathrm{Si}$ subsequently crystallizes to a crystalline $(\mathrm{Li}, \mathrm{Si})$ compound. The nature of this crystallization process is not known.

It is widely accepted that highly lithiated a- $\mathrm{Li}_{\mathrm{x}} \mathrm{Si}$ can only crystallize to either $\mathrm{Li}_{15} \mathrm{Si}_{4}$ or $\mathrm{Li}_{22} \mathrm{Si}_{5}[2,3]$. It has been observed that the crystallization from the amorphous phase occurs "quickly" based on recent in situ XRD and TEM studies[4, 5]. In situ S/TEM observation provides a unique opportunity to reveal the fine details of such complex phase transformations. In this paper, we use in situ S/TEM and EELS to probe the structural and chemical evolution and phase transformation mechanisms of electrochemical driven lithiation of silicon. In addition, DFT calculations were conducted to understand the crystallization of the amorphous to the crystalline phase in lithiated Si.

The lithiation behavior and microstructural features of single crystalline silicon nanowire were generally illustrated in Figure 1. It has been very well documented in literature that the lithiation of silicon nanowire proceeds in the core-shell structured fashion. This is clearly illustrated by the TEM image of Figure 1, where the core of silicon is revealed by the diffraction contrast. The lithiated shell is amorphous a- $\mathrm{Li}_{\mathrm{x}} \mathrm{Si}$. The core-shell structure is related to the fast diffusion of $\mathrm{Li}$ at the surface of the silicon nanowire. The formation of $\mathrm{c}-\mathrm{Li}_{15} \mathrm{Si}_{4}$ from the $\mathrm{a}-\mathrm{Li}_{\mathrm{x}} \mathrm{Si}$ is very unique, which is characterized by the rapid transformation of the amorphous a- $\mathrm{Li}_{\mathrm{x}} \mathrm{Si}$ to crystalline $\mathrm{c}-\mathrm{Li}_{15} \mathrm{Si}_{4}$ when the $\mathrm{x}$ reaches a critical value. It has been observed that following the crystallization of c- $\mathrm{Li}_{15} \mathrm{Si}_{4}$ from the $\mathrm{a}-\mathrm{Li}_{\mathrm{x}} \mathrm{Si}$, neither phase segregation happens nor residual phase was formed, indicating that the critical value of $\mathrm{x}$ for this phase transformation is $\mathrm{x}=3.75$.

One of a sensible questions that needs to be answered is why the crystallization of $\mathrm{Li}_{15} \mathrm{Si}_{4}$ $\left(x=3.75\right.$ in $\left.a-\mathrm{Li}_{\mathrm{x}} \mathrm{Si}\right)$, rather than other compounds with a relatively low value of $\mathrm{x}$ in the a$\mathrm{Li}_{x} \mathrm{Si}$ such as $\mathrm{LiSi}(\mathrm{x}=1), \mathrm{Li}_{12} \mathrm{Si}_{7}(\mathrm{x}=1.71), \mathrm{Li}_{7} \mathrm{Si}_{3}(\mathrm{x}=2.33)$, and $\mathrm{Li}_{13} \mathrm{Si}_{4}(\mathrm{x}=3.25)$, because the $\mathrm{x}$ value in the $\mathrm{a}-\mathrm{Li}_{\mathrm{x}} \mathrm{Si}$ increases gradually from low to a higher value and these compounds indeed exists as evidenced from the phase diagram of Li-Si. Our DFT simulation provides insight into this question. For the crystalline Li-Si alloys, the splitting between the $3 s$ and $3 p$ states grows larger as the Li concentration increases to 4.4 $\left(\mathrm{Li}_{22} \mathrm{Si}_{5}\right)$ per $\mathrm{Si}$. The distribution of the $3 s$ and $3 p$ states becomes narrower with increasing $\mathrm{Li}$, which is attributed to the decreasing in the Si-Si bond interactions. The changes of the $3 s$ and $3 p$ states in the amorphous Li-Si alloys also show the same trend. Apparently, the electronic structure of a- $\mathrm{Li}_{\mathrm{x}} \mathrm{Si}$ approaches that of the corresponding crystalline phase as $\mathrm{x}=>3.75$. The congruent phase transformation characteristic of a- $\mathrm{Li}_{3.75} \mathrm{Si}$ to $\mathrm{c}-\mathrm{Li}_{15} \mathrm{Si}_{4}$ does 
not involve large scale atomic motion. However, it will involve local bonding configuration changes.

\section{References}

[1] P. Limthongkul, Y. I. Jang, N. J. Dudney, and Y. M. Chiang, Acta Materialia 51 (2003) 1103.

[2] C.-M. Wang, X. Li, Z. Wang, W. Xu, J. Liu, F. Gao, L. Kovarik, J.-G. Zhang, J. Howe, D. J. Burton, Z. Liu, X. Xiao, S. Thevuthasan, and D. R. Baer, Nano Letters 12 (2012) 1624.

[3] M. T. McDowell, I. Ryu, S. W. Lee, C. M. Wang, W. D. Nix, and Y. Cui, Adv. Mater. 24 (2012) 6034.

[4] H. Ghassemi, M. Au, N. Chen, P. A. Heiden, and R. S. Yassar, Acs Nano 5 (2011) 7805.

[5] X. H. Liu, L. Q. Zhang, L. Zhong, Y. Liu, H. Zheng, J. W. Wang, J. H. Cho, S. A. Dayeh, S. T. Picraux, J. P. Sullivan, S. X. Mao, Z. Z. Ye, and J. Y. Huang, Nano Letters 11 (2011) 2251.

[5] Acknowledgement: This work was supported by the Laboratory Directed Research and Development (LDRD) program of Pacific Northwest National Laboratory. The work was conducted in the William R. Wiley Environmental Molecular Sciences Laboratory (EMSL), a national scientific user facility sponsored by DOE's Office of Biological and Environmental Research and located at PNNL. PNNL is operated by Battelle for the DOE under Contract DE-AC05-76RLO1830.

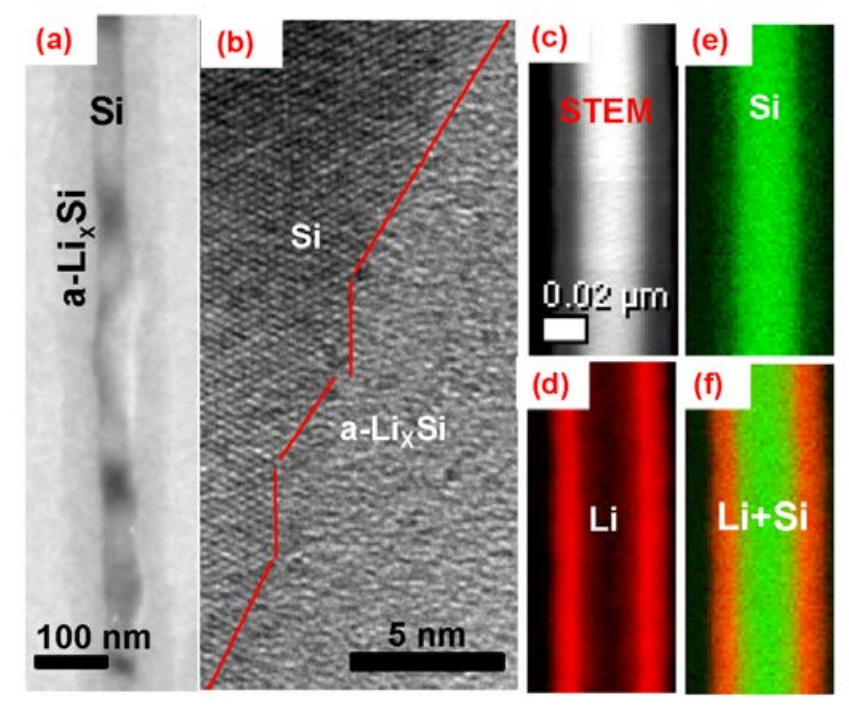

Fig. 1 General microstructual features, showing the core-shell lithiation behavior of silicon nanowire. (a) TEM image reveals a Si core cladded with an a-Li $\mathrm{S}_{\mathrm{x}} \mathrm{Si}$ shell. (b) Atomic resoution TEM image revealing the interface between the a- $\mathrm{Li}_{\mathrm{x}} \mathrm{Si}$ and $\mathrm{Si}$ is atomically sharp and the $\mathrm{Si}$ is faceted along some crystallographic planes. (c) STEM image showing the $\mathrm{Si}$ core and $\mathrm{a}-\mathrm{Li}_{\mathrm{x}} \mathrm{Si}$ shell. (d) Li distribution by EELS mapping. (e) $\mathrm{Si}$ distribution by EELS maping. (f) Li and Si distribution. 